\title{
MICROTREMOR VIBRATIONS IN THE SOIL EXPERIMENTAL INVESTIGATION AND FEM SIMULATION
}

Vibration problems of the building structures caused by technical seismicity are becoming increasingly topical. The aim of this paper is to show FEM simulation of the spreading wave impact, which causes vibration system consisting of subsoil-structure interaction in microtremor. The results of the experiment together with this theoretical analysis and FEM simulation appear to be effective application for engineering experience. They are also used in assessing and predicting the vibration effects induced by technical seismicity due to traffic. [1].

Keywords: FEM simulation, vibration, response, spectrum, soil, interaction.

\section{Introduction}

The FE simulations and experimental measurements are used for the purpose of designing and evaluating the structures. However, the experimental measurements are often economically challenging and time-consuming. In the area of structural dynamics, the assessment structure is based on the dynamic response of the structure due to dynamic loading. Each standard has criteria for evaluating the dynamic response. For these purposes appropriate methodology of the FEM simulation can be applied. Load of technical seismicity requires precise approach to creating a FEM model. During the FEM model creation it is necessary to consider the interactive dynamic area. This paper contains a case study of the FEM simulation of the dynamic response of the model due to the mechanical impact load. The analytical results are compared with the experimental measurement "in situ“. For the purpose of the case study a real single-family house was chosen. It is located close to the railway line, which produces dynamic effects due to technical seismicity. The house of this type was selected as the most frequent building located near the railway line in Slovakia.

\section{Description of the analysed object and its locality}

The analysed object is a real single-family house located in the city of Zilina, in the area of Strazov. Strazov is situated in the western part of Zilinska Lehota and Dolny Hricov. In the eastern side it is separated from Zilina by the Rajcanka river. In the south it borders on the urban parts of the gardening area. In the northern side of Strazov there is a reservoir called the Hricov dam, city part Povazsky Chlmec and a village named Divinka. The investigated object (Fig. 1) is the house (built in 1962) which has an irregular floor plan and the built-up area is 91.72 square meters.
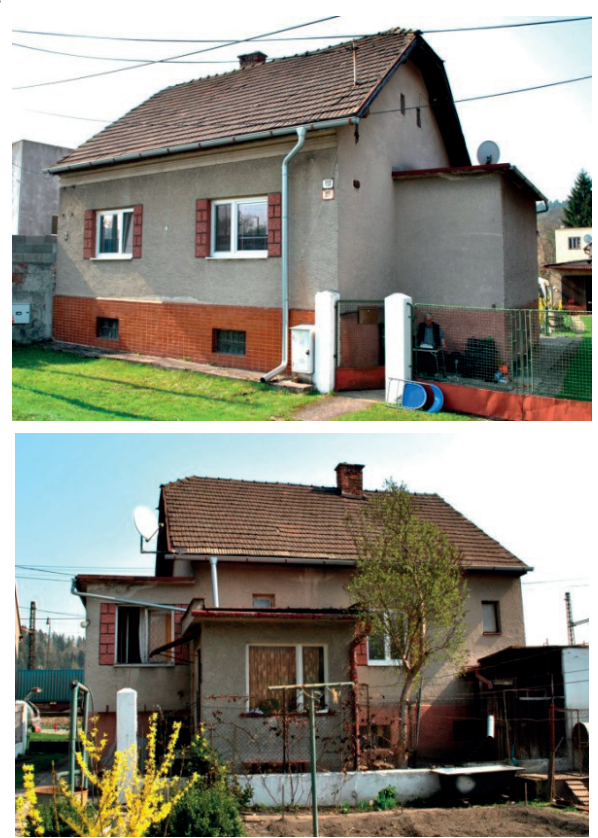

Fig. 1 The views on the single-family house

Its layout is spread over two floors and the whole surface basement. The attic serves as a storage. Perimeter and interior load bearing walls (the thickness of $450 \mathrm{~mm}$ and $300 \mathrm{~mm}$ ) are built of traditional baked bricks on lime-cement mortar. Non-

\footnotetext{
* Zuzana Papanova, Daniel Papan, Jan Kortis

Department of Structural Mechanics, Faculty of Civil Engineering, University of Zilina, Slovakia

E-mail: zuzana.papanova@fstav.uniza.sk
} 
bearing interior walls are made of bricks. Ceilings are reinforced, thickness $200 \mathrm{~mm}$, reinforcing wreaths are also reinforced concrete, monolithic concrete class C 20/25 and steel 10505 (R). The building is covered with a saddle-shaped roof with a slope of $40^{\circ}$. The roof load bearing structure is created from a standing stool. The room flooring (ceramic tiles and wood floors) are distributed inside. Access to the ground floor and the basement is provided with a wooden staircase (Fig. 2).
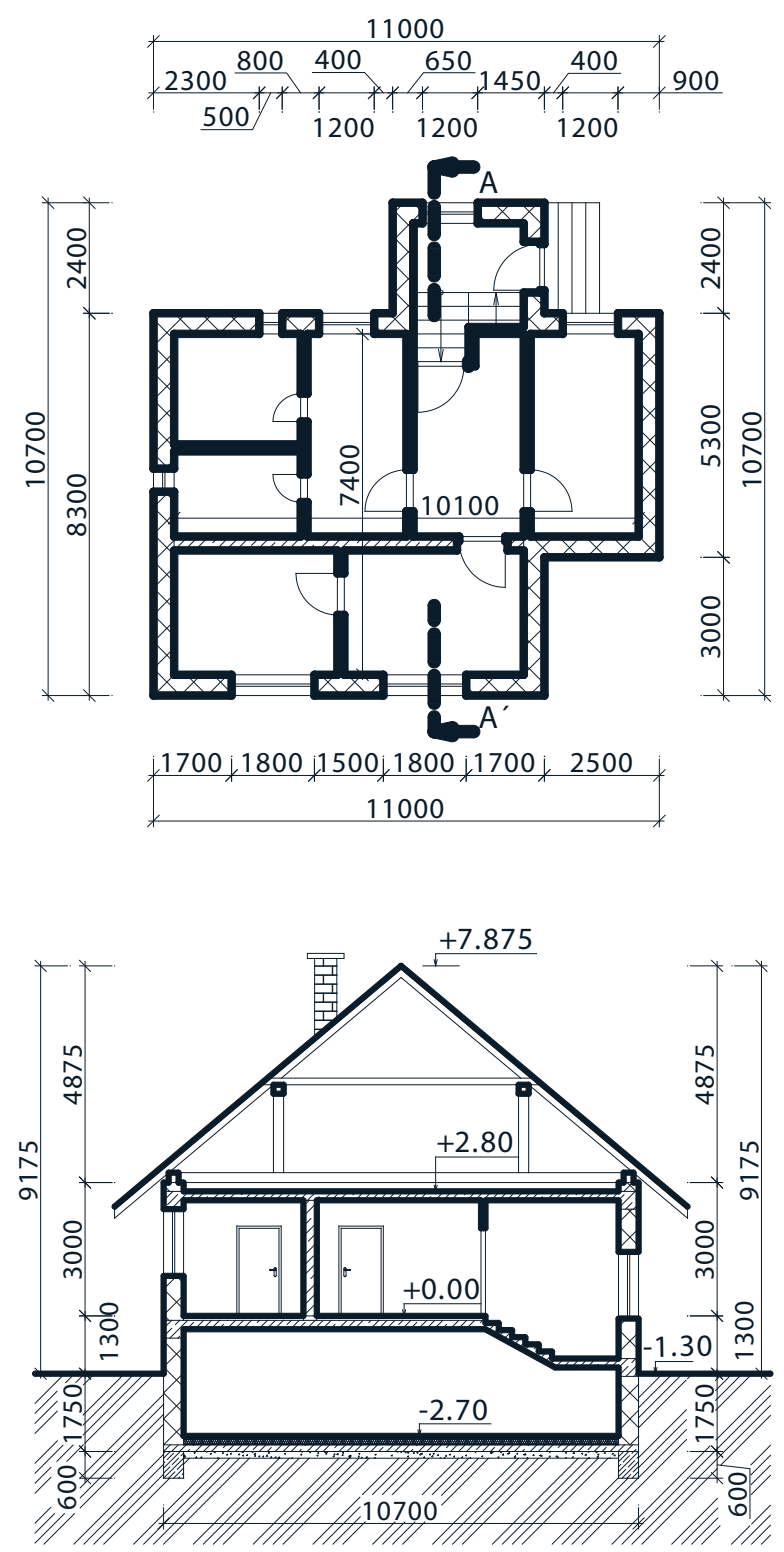

Fig. 2 Plan and cross-section of the single-family house

\section{Soil dynamic diagnostics and experimental investigation}

The pursued objectives of the measurement were carried out in two phases. The impulse - seismic method (ISM) was applied in the first phase. The ISM is based on the surface wave propagation in the form of pulses from the impact source. The second phase was to carry out an experimental evaluation of the basic soil parameters. Experimental devices used during measurements are shown in Fig. 3.

Dynamic response of real environment (half-space) response loaded by impulse excitation was measured using a set of five accelerometers with a frequency range of $1 \div 4000 \mathrm{~Hz}$. (BruelKjaer). The accelerometers were placed in drilled ground holes and on the object (Fig. 4). The accelerometers measured response in the vertical direction. Dynamic response in the observed points were measured in the form of vibration velocities $(\mathrm{m} / \mathrm{s})$, in three orthogonal directions $x, y, z$. The measurement was performed using the "off - line" method. The recorded signals are simultaneously saved in two PCs - AMILO and PC FS (NI Compact DAQ software). Evaluation of the measured data was carried out in laboratory conditions of the Department of Structural Mechanics (DSM), Faculty of Civil Engineering (FCE), University of Zilina based on the evaluation of software lines DSM.

The measuring unit consisted of:

- piezoelectric accelerometers BK 8306 (Bruel - Kjaer) - 5pcs,

- integration amplifier BK-2693-014 (Brüel-Kjaer), measuring Notebooks,

- AD converters NI Compact DAQ (NI - National Instrument).

Mechanical movement in the measuring points was transformed by measuring line of accelerometers from an electrical signal after amplification and integration to the vibration acceleration $-a(t)$ and vibration velocity $-v(t)$. It was conducted by means of shielded cables to the measuring center near the object. Notebooks were calibrated with NI Compact DAQ AD converters. The analog signal was recorded and saved using NI Lab View software with the sampled frequency $f_{\mathrm{s}}=1000 \mathrm{~Hz}$ (the required criteria for sampling signals is $\Delta \mathrm{t}<1 / 2 f_{\max }$ ).

Impulse device location and the position of the measured points are schematically shown in Fig. 4. In this case, the experimental finding of soil environment vibration intensity due to impact excitation and its frequency transfer were performed. Excitation signals were propagated as a surface and shear wave from the source. These signals had the stochastic character with the variable performance in time and space. For further analysis the characteristics of an ideal the elastic half space can be used for the soil. 

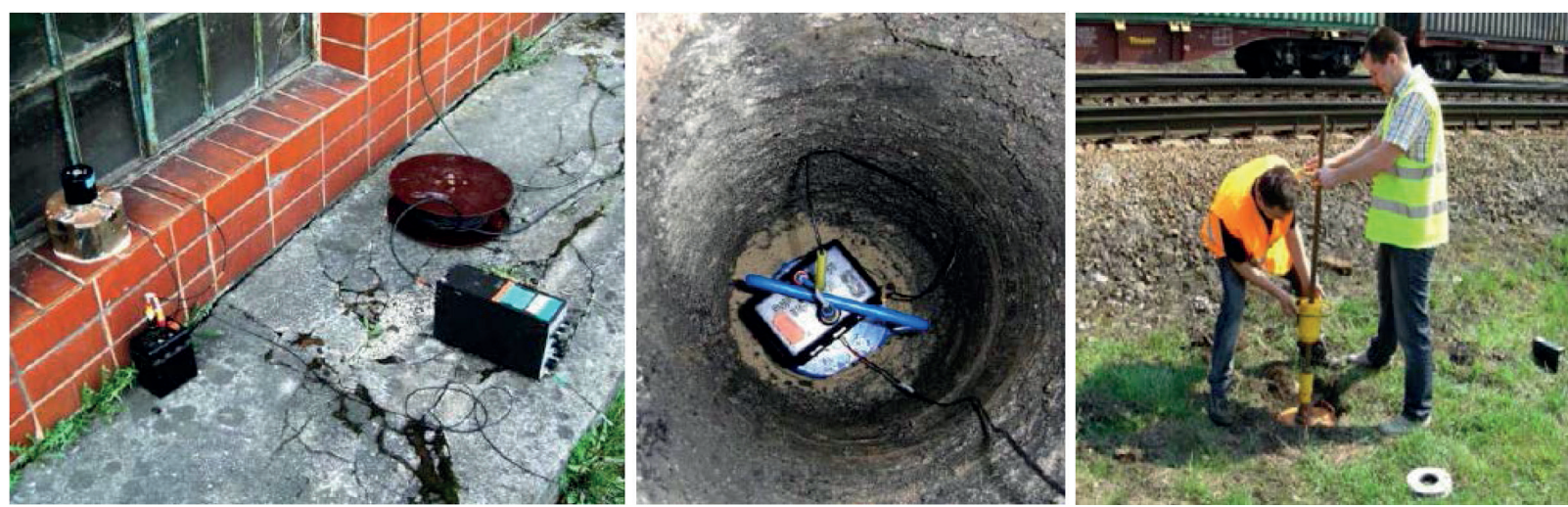

Fig. 3 Accelerometers installed in soil and on structure, ISM procedure

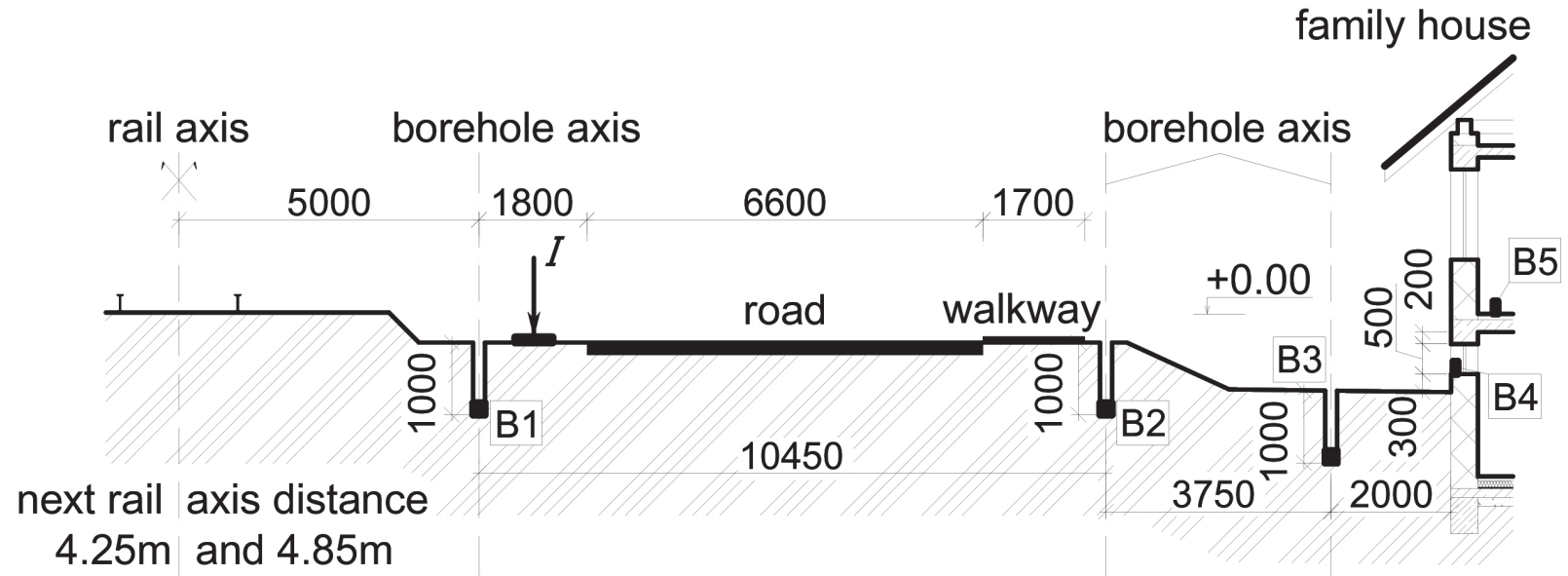

Fig. 4 Experimental measurement scheme

In order to obtain the velocities time histories of vibration in the observed geological location due to impulse, it was necessary to establish the basic soil dynamic parameters. The impulse seismic method (ISM) was used in this case as a simple way to get the basic soil parameters. In the calculations of elastic modulus of the investigated natural environment the following mechanical characteristics were needed:

- $v \approx 0.33$ (Poisson ratio)

- unit weight $\rho_{13} \approx 1760 \mathrm{~kg} / \mathrm{m}^{3}$ (for sandy clays and gravels, point B1 - B3),

- unit weight $\rho_{34} \approx 1600 \mathrm{~kg} / \mathrm{m}^{3}$ (the sample weight, clays and sandy clays, point B3 - B4).

Velocity of surface waves $\left(C_{R}\right)$ was measured between the points B1-B3 and B3-B4. The corresponding power spectra $\operatorname{Gii}(f)$ and cross power spectra $G_{i k}(f)$ together with the coherence function $\gamma_{34}^{2}(f)$ and transfer characteristic or gain factor $H_{i k}(f)$ calculated from the vibration velocity time histories of pulse load in points $v_{3}(t)-v_{4}(t)$ are shown in Fig. 6 as an analysis preview.
Velocities of Rayleigh surface waves were observed using an analysis of the correlation [2] - cross correlation function $R_{i k}(\tau)$ :

the sandy clays and gravels point B1 - B3 compact road subsoil and pavement from 0.0 to $4.0 \mathrm{~m}$ level below the surface (Impulses) $C_{R} \approx 128-132 \mathrm{~m} / \mathrm{s}$,

for clays and sandy clays point B3 - B4, subsoil at 1.0 to $5.0 \mathrm{~m}$ level below the surface (Impulses) $C_{R} \approx 92-98 \mathrm{~m} / \mathrm{s}$.

For investigated soil environment $(v \approx 0.33)$ the correlation between Rayleigh surface and shear wave velocity [3] can be evaluated in the equation (1).

$C_{S}=\frac{C_{R}}{0.93} \cdot[\mathrm{m} / \mathrm{s}]$

Seismic modulus of elasticity in shear strength-pressure is then calculated from the equation (2):

$G_{0}=C_{S}^{2} \rho, \quad E_{0}=2 G_{0}(1+v) \quad[\mathrm{MPa}]$.

Substituting the average value of wave velocity to (2) the elastic modulus parameter [4] was calculated for: 


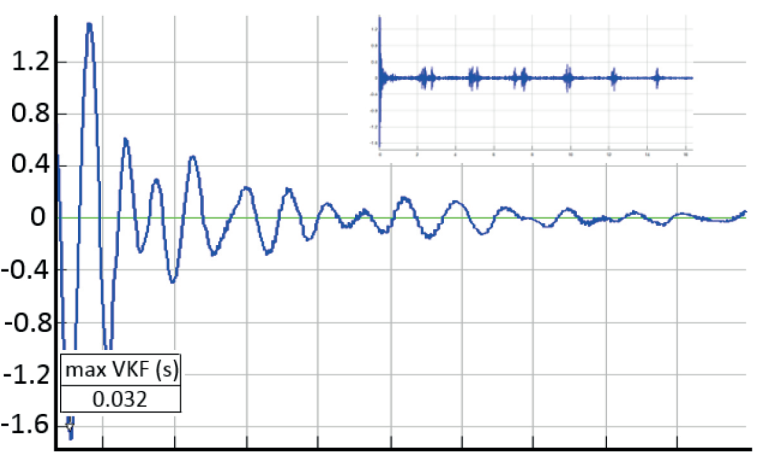

(s) $\begin{array}{lllllllll}0.06 & 0.12 & 0.18 & 0.24 & 0.30 & 0.36 & 0.42 & 0.48 & 0.54\end{array}$

\section{a) Cross-correlation function $R_{34}(f)$ measurement 2.}

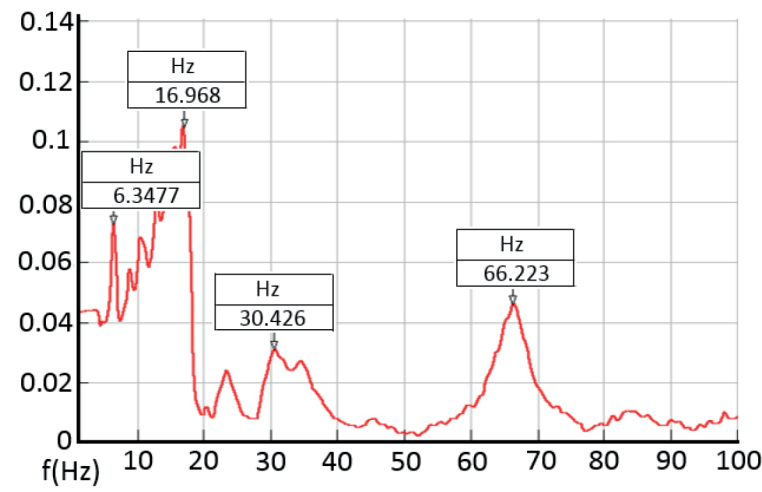

c) Gain factor $\mathrm{H}_{34}(f)$ measurement 2.

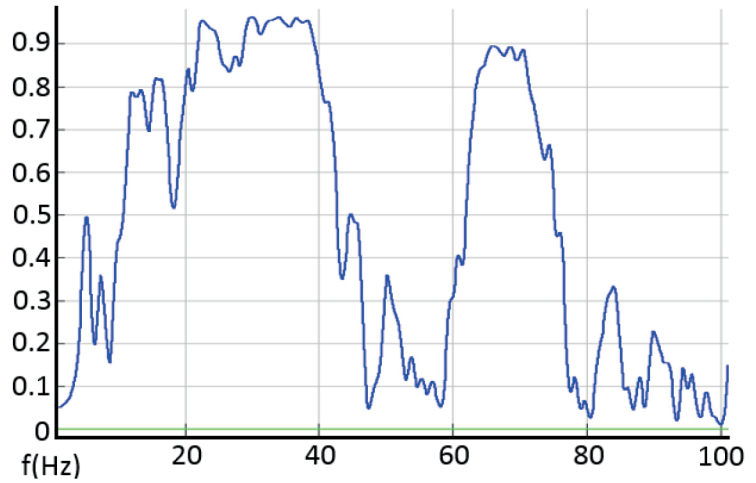

b) Coherence function $\gamma_{234}(f)$ measurement 2 .

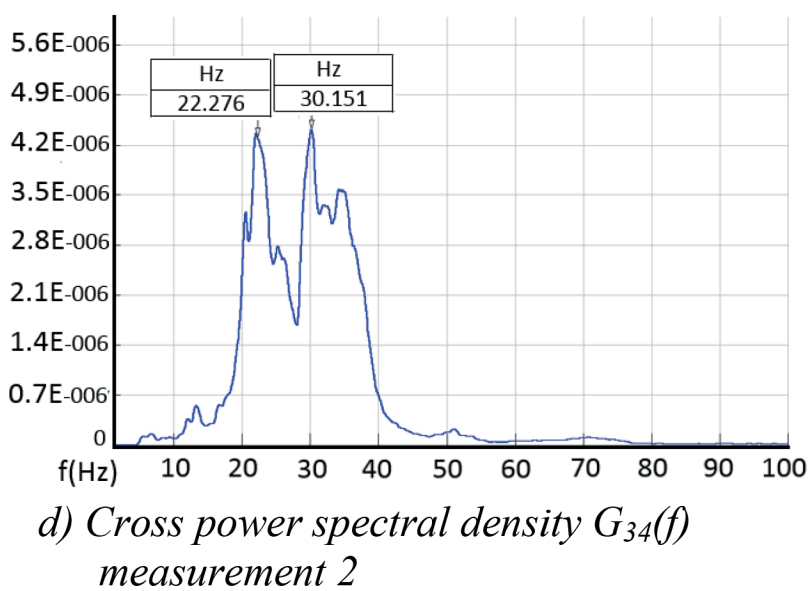

Fig. 5 The ISM-Analysis of impulses in the time and frequency domains in points B3, B4

- subsoil (points B1-B3, $\rho_{13}=1760 \mathrm{~kg} / \mathrm{m}^{3}$ )

$E_{0} \approx 77.33[\mathrm{MPa}], G_{0} \approx 29.74[\mathrm{MPa}]$,

- $\quad$ subsoil - foundation of the house (points B3-B4, $\rho_{34}=1600$ $\left.\mathrm{kg} / \mathrm{m}^{3}\right)$

$E_{0} \approx 39.42[\mathrm{MPa}], G_{0} \approx 14.40[\mathrm{MPa}]$.

Attenuation parameter $\alpha_{R}$, according to material and geometric characteristics of the soil environment damping in frequency range $(0-100 \mathrm{~Hz})$ had the following averaged values: $\alpha_{\mathrm{R}}$ $\approx 0.286 \mathrm{~m}^{-1}$ (measurement series 1 and 2 ).

Frequency response characterized by cross power spectral density $G_{i k}(f)$ or gain factor $H_{i}(f)$ can determine the most suitable impulse excitation. A wide range of excitation frequencies from passing trains is not included in this transmission. The subsoil has a dominant band of transmission frequencies: $f_{D I}=20 \div 52$ $\mathrm{Hz}$. The example of ISM procedure analysis functions is shown in Fig. 5.

\section{FEM simulation of the vibrations transmission} in the soil

The finite element method as the most widely used numerical method for finding approximate solution is used for modelling the wave propagation in the elastic subgrade. This phenomenon is governed by the following equation

$M \ddot{U}+C \dot{U}+K \quad U=R$

Solution of the equation is reached by the central difference method which assumed that the first derivative is

${ }^{t} \dot{\mathrm{U}}=\frac{1}{2 \Delta t}\left(-{ }^{t-\Delta t} \mathrm{U}+{ }^{t+\Delta t} \mathrm{U}\right)$

and second derivative is

${ }^{t} \mathrm{U}=\frac{1}{\Delta t^{2}}\left({ }^{t-\Delta t} \mathrm{U}-2{ }^{t} \mathrm{U}+{ }^{t+\Delta t} \mathrm{U}\right)$

The governing equation is given in the following form 


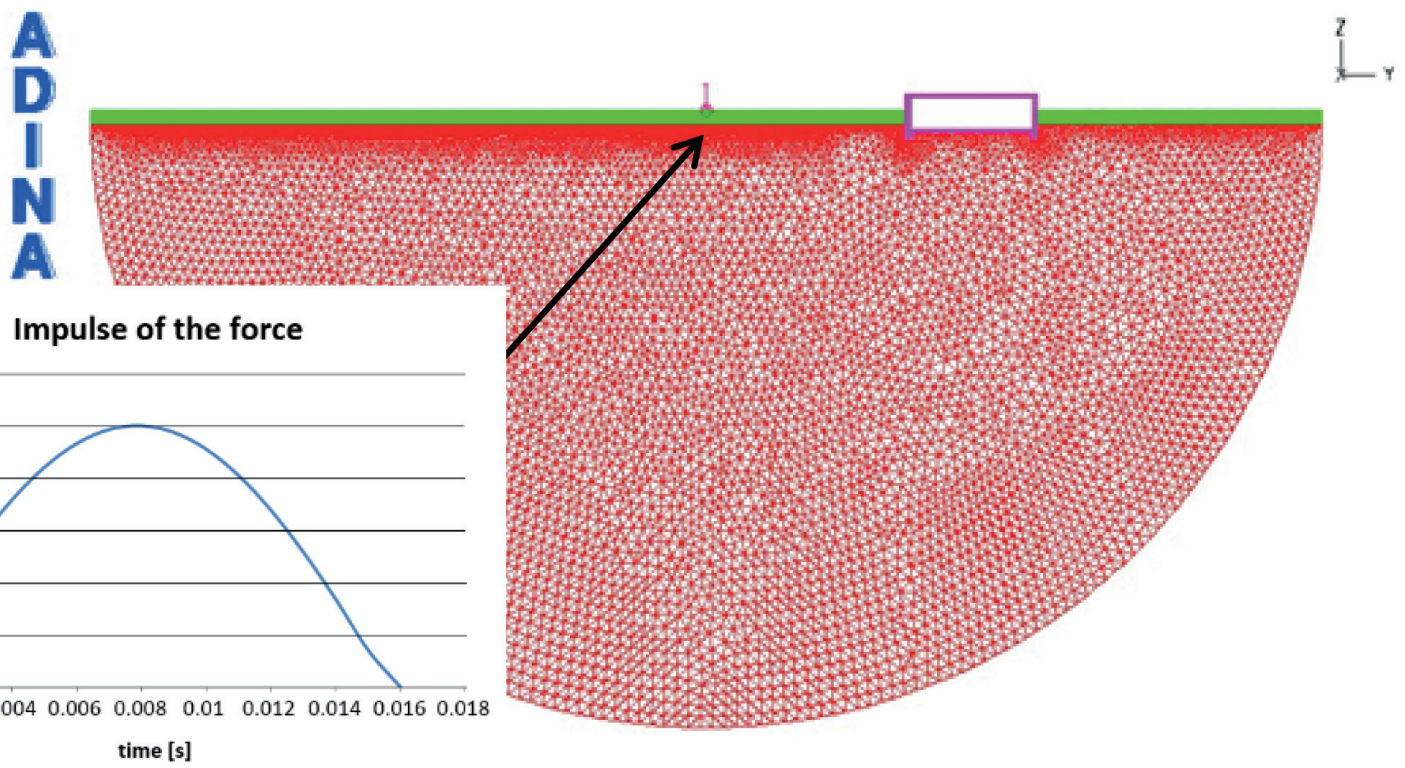

Fig. 6 The model for numerical simulation with dynamic load

$$
\mathrm{M}{ }^{t} \ddot{\mathrm{U}}+\mathrm{C}{ }^{t} \dot{\mathrm{U}}={ }^{t} \mathrm{R}+{ }^{t} \mathrm{~F}
$$

Substituting for ${ }^{t} \dot{U}{ }^{t} \ddot{U}$ we obtain

$$
\begin{aligned}
& \left(\frac{1}{\Delta t^{2}} \mathrm{M}+\frac{1}{2 \Delta 1} \mathrm{C}\right)^{t+\Delta t} \ddot{\mathrm{U}}={ }^{t} \mathrm{R}+{ }^{t} \mathrm{~F}+\frac{2}{\Delta t^{2}} \mathrm{M}^{t} \mathrm{U}- \\
& \left(\frac{1}{\Delta t^{2}} \mathrm{M}+\frac{1}{2 \Delta 1} \mathrm{C}\right)^{t+\Delta t} \mathrm{U}
\end{aligned}
$$

It can be used to solve the value ${ }^{t+\Delta t} \mathrm{U}$.

The ADINA software was used for the soil vibration simulation. This software is used to do the numerical simulation because it offers the explicit dynamic analysis which is based on the central difference method. This method is appropriate for the solution of wave propagation. The geometry of the model is defined in a plane. It means that the spacious character of the wave propagation is neglected. The result is that the amount of equations is lower and there is no problem with solution of the simulation by using a common computer. The shape of a halfcircle with a diameter of 50 meters is used to define the subgrade. The zero displacements are prescribed at the edge of the model (Fig. 6). This can be done because the width of the model is longer than the wave can pass during the time of the simulation. It means that the wave does not bounce back from the edge of the model.

The defined material characteristics of the subgrade are comparable with the values obtained from experimental analysis. The walls of the house are made as brick structures and the flooring plate is made of concrete. Results in the time domain for whole $F E$ field in several time steps are shown in Fig. 7. (FE displacement)
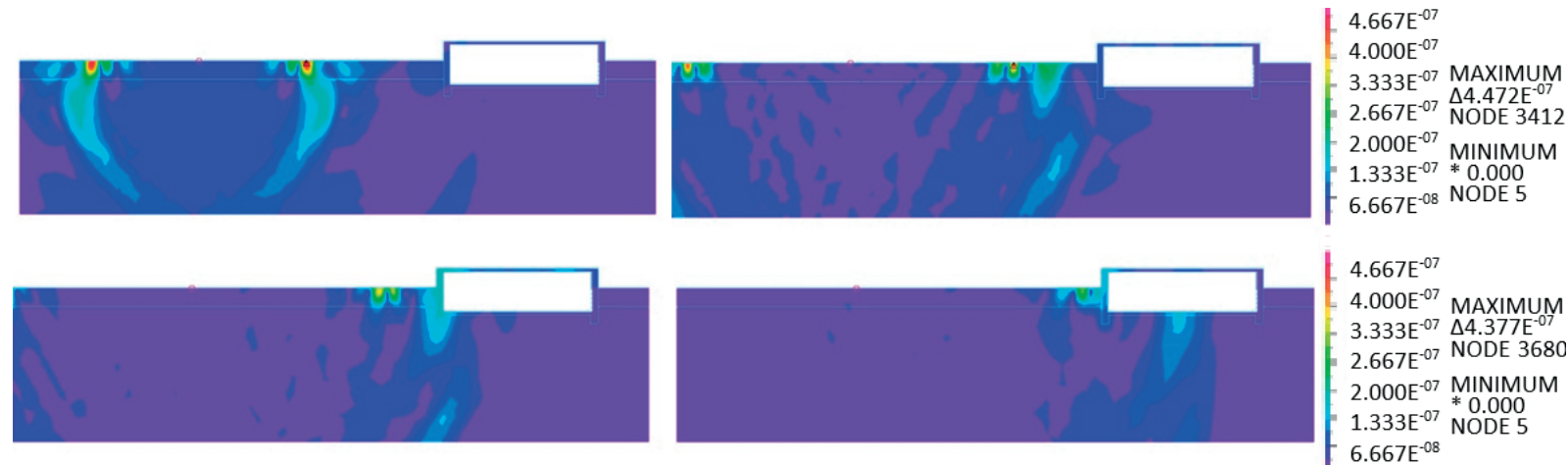

$4.667 \mathrm{E}^{-07}$

4.000E -07 MAXIMUM

$3.333 \mathrm{E}^{-07} \triangle 4.377 \mathrm{E}^{-07}$

$2.667 \mathrm{E}^{-07}$ NODE 3680

$2.000 \mathrm{E}^{-07}$ MINIMUM

$1.333 \mathrm{E}^{-07} * 0.000$

$6.667 \mathrm{E}^{-08}$

Fig. 7 Displacement magnitude in time $t$ (sec) 


\section{Experimentand comparison of FEM results}

FEM simulation was performed in the time domain. The measured power pulse was used as load. For dynamic load the pulse shape divided into time steps $0.001 \mathrm{sec}$. was considered in order to compare the results with experiment. The time duration of the pulse load $0.016 \mathrm{sec}$ was determined experimentally.
Force amplitude reached the value of $50 \mathrm{~N}$. These values were statistically evaluated as the average parameters. The results of FEM simulation in time and frequency domains are shown in Fig. 8. The time histories from experimental measurements are in relatively good accordance with the time histories obtained from $F E$ simulation in points B1-B5. Time shifts between Rayleigh and shear waves propagation are identical. Particle velocities are not so identical due to inhomogeneity of the soil [5].

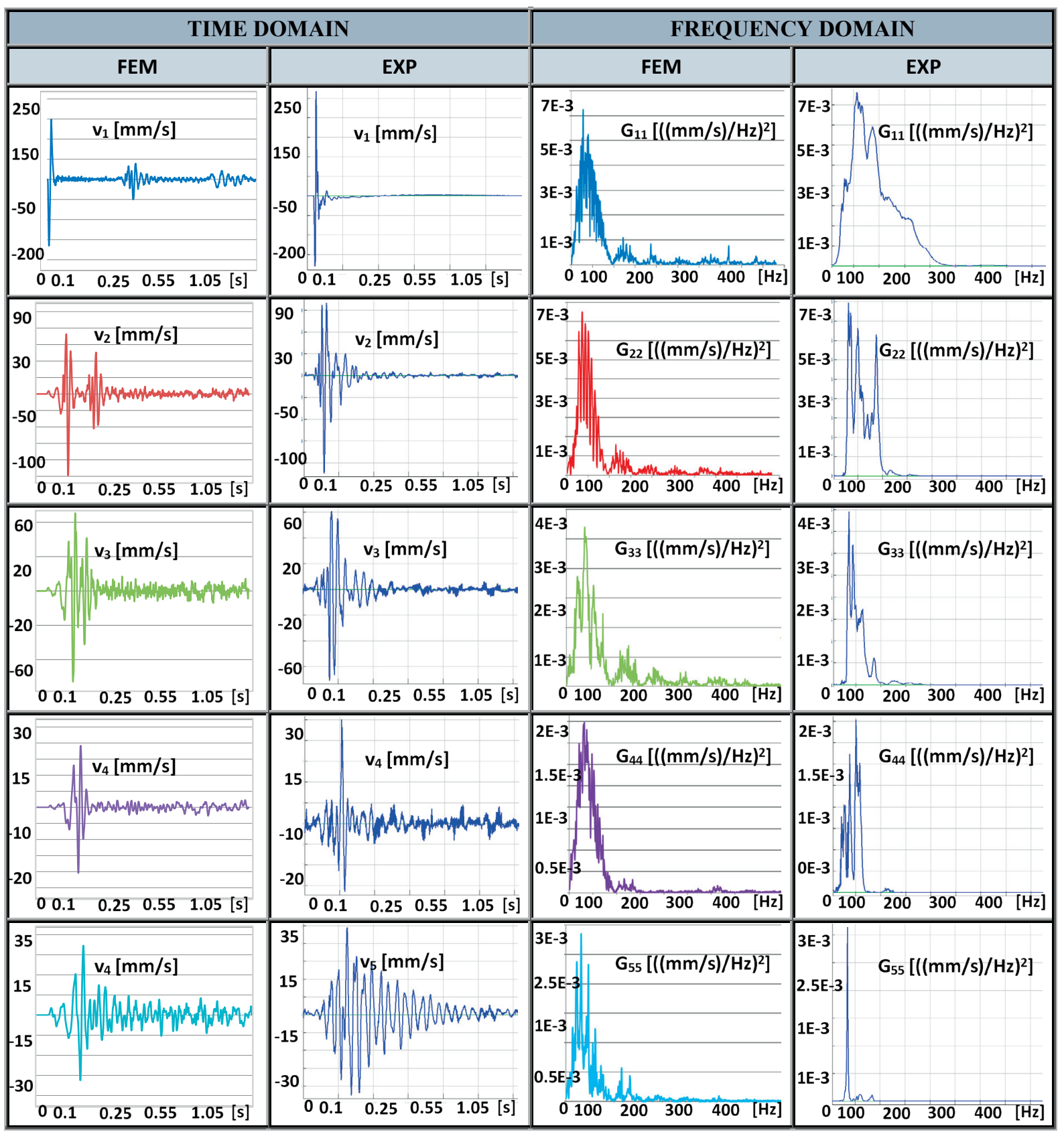

Fig. 8 FE and experimental comparison in time and frequency domains (points B1 - B5) 


\section{Conclusions}

Problems with the vibrations of civil structures due to technical seismicity resources are current. Soil-borne vibrations and their effects on civil structures can be solved theoretically (using FEM simulations) and can also be detected experimentally [6]. Experimentally obtained dynamic response of the structure is an objective basis for the structure evaluation loaded by technical seismicity effects. Measurements are not possible in the case of new buildings (designed near technical seismicity sources). In this case it is possible to measure the dynamic response in the reference points for future civil structure. These measured records can be used as a dynamic load for $F E$ model. In such simulation, however, the soil-structure interaction can not to be considered. The case study shows the possibility of using complex modeling layered soil with structure interaction. The results obtained by FEM simulation are in good accordance with the experiment. It is necessary to know the basic parameters of the soil for the complex computing model. These parameters can be easily detected using the ISM method. The most effective method to estimate the effects of the technical seismicity on structures can be the combination of theoretical - FEM simulation and experimental measurements [7] .

\section{Acknowledgement}

This paper was created with the support of the OP Education for the project "Education quality support and research for the transport sector as the engine of the economy" (ITMS: 26110230076), which is co-financed by the European Social Fund.

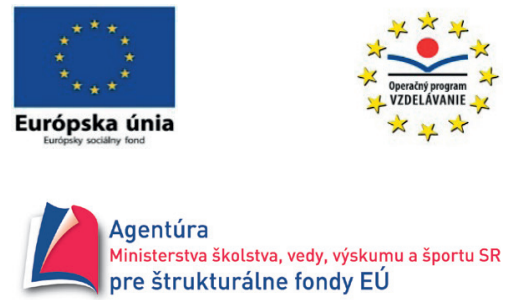

Modern education for the knowledge society / Project co-financed from EU sources.

\section{References}

[1] JUHASOVA, E.: Action of Seismic Motions on Building Structures. Veda, Bratislava, 1985

[2] BENDAT, J. S., PIERSOL, A. G.: Engineering Applications of Correlation and Spectral Analysis. Wiley : New York, 1980

[3] RAYLEIGH, J. W.: On Waves Propagation along the plane Surface on Elastic Solid. Proc. Math. Soc., London, 1885

[4] DECKY, M., DRUSA, M., PEPUCHA, L., ZGUTOVA, K.: Earth Structures of Transport Constructions. Pearson Education Limited, 2013, Edinburg Gate : Harlow : Essex CM20 2JE. Edited by Martin Decky, p. 180, ISBN 978-1-78399-925-5.

[5] POLAK, M., PLACHY, T., ROTTER, T.: Vibration Monitoring of the Bridge Loaded by Heavy Vehicle Traffic, $5^{\text {th }}$ WSEAS intern. Conference on Applied and Theoretical Mechanics Location, Puerto de la Cruz, 2009, 120-123.

[6] BENCAT, J., STYPULA, K.: Buildings Structure Response Due to Railway Traffic. Communications - Scientific Letters of the University of Zilina, vol. 15, No. 2, 2013, 41-48. ISSN 1335-4205.

[7] COUliER, P., FRANCOIS, S., DEGRANDE, G., et al.: Subgrade Stiffening Next to the Track as a Wave Impeding Barrier for Railway Induced Vibrations. Soil Dynamics and Earthquake Engineering, vol. 48, 2013, 119-131. ISSN 0267-7261. 